\title{
Parsimonious relations between Guitar Textural Proposals
}

\author{
Bernardo Ramos Pinto e Pauxy Gentil-Nunes \\ Universidade Federal do Rio de Janeiro | Brazil
}

\begin{abstract}
Resumo: A Análise de Textura Violonistica é uma proposta analítica direcionada à composição para violão que expõe as relações entre a estrutura textural e os procedimentos técnicos utilizados na performance instrumental. As Propostas Texturais Violonisticas (PTVs) são as configuraçốes específicas extraídas através deste processo analítico. No presente trabalho, o foco reside no reconhecimento de movimentos parcimoniosos entre PTVs, isto é, distinções mínimas entre padrôes texturais relacionados a determinados usos do instrumento. Parcimoniosidade define-se no contexto das teorias da Variação Progressiva, Neoriemanniana e Análise Particional. Os trabalhos prévios de Fabio Adour e dos autores Sérgio Freire e Pedro Cambraia apresentam perspectivas sobre a relação entre textura e performatividade violonística. A série de peças progressivas Études Simples, de Leo Brouwer, é adotada como referência. O trabalho traz como resultado uma proposta de ordenamento em rede de configurações técnico-texturais conectadas por relações parcimoniosas.
\end{abstract}

Palavras-chave: Composição, Violão, Textura Musical, Análise Musical, Leo Brouwer.

\begin{abstract}
Guitar Textural Analysis is an analytical proposal devised for the composition for the guitar that exposes the relations between the textural structure and the technical procedures used in the instrumental performance. The Guitar Textural Proposals (GTPs) are the specific configurations extracted in this analytical process. In the present work, the focus remains on recognizing parsimonious movements between GTPs, that is, minimal distinctions between patterns of use of the instrument combined with respective textural configurations. Parsimoniousness is defined in the context of Developing Variation, Neo-Riemannian Theory, and Partitional Analysis. Previous works by Fabio Adour and authors Sérgio Freire and Pedro Cambraia present perspectives on the relation between texture and guitar performance. Leo Brouwer's series of progressive pieces Etudes Simples is adopted as a reference. The work results in a proposal for a ordered network of technical-textural configurations connected by parsimonious relations.
\end{abstract}

Keywords: Composition, Acoustic Guitar, Musical Texture, Musical Analysis, Leo Brouwer. 
$\mathrm{P}$ arsimonious leading is a metaphor widely used in Western music theory and practices, being observed in the fundamentals of counterpoint, the voice-leading of tonal harmony, or in compositional and analytical procedures of the XX and XXI centuries. Ethan Haimo (1996), for example, presents a proposal for analyzing Schoenberg's works based on one of his composition concepts: the Developing Variation. He departs from conceiving the process of variation as a compositional procedure divisible into minimal steps. From there, one can comparatively observe a musical object and its relations with derived variations.

(...) we can deduce what kinds of transformations a motive can undergo in the process of developing variation. Intervals can be expanded, contracted, rearranged, inverted, and reversed in order; notes can be added to the beginning or the end or inserted in the middle; durations can be augmented, diminished, and shifted in metric position; pitches can be doubled, repeated, and transferred to other registers. (HAIMO, 1996, p. 193).

These procedures can be arranged in order to determine a parsimonious route that leads the original structure step by step to a particular derived version.

(...) if the changes are made gradually, it is possible to transform a motive so completely that a later manifestation might be thought of as a dramatically contrasting idea when compared directly with the original, but still can have been achieved by an eminently logical, and easily audible, process of organic development. (ibid., p. 193).

The research literature on parsimonious movements or transformations in pitch and rhythmic fields is vast, including all the analytical works based on Developing Variation. ${ }^{1}$ In the scope of harmony, the Neo-Riemannian theory is also based on the idea of adjacency relations between harmonic entities:

The neo-Riemannian response recuperates a number of concepts cultivated, often in isolation of each other, by individual nineteenth-century harmonic theorists. The following exposition identifies six such concepts: triadic transformations, common-tone maximization, voice-leading parsimony, "mirror" or "dual" inversion, enharmonic equivalence, and the "Table of Tonal Relations". (COHN, 1998)

\footnotetext{
${ }^{1}$ Walter Frisch (1984) proceeds a detailed analytical work on Brahms procedures from the perspective of Developing Variation. Stephen Collisson (1994) analyses Arnold Schoenberg's string quartets based on Grundgestalt and Developing Variation concepts.
} 
Richard Cohn, for example, demonstrated "the potential of consonant triads to engage in parsimonious voice leading” (1997, p. 2), considering a family of trichord transformations that consists of two features: the maintenance of two notes and the articulation by the minimal movement of the third one (half or whole step). This family comprises three basic operations: L (leading), P (parallel), and R (relative; see Figure 1). Cohn shows, by mathematical proof, that the only set class that allows such parsimonious transformations between its internal elements is [037], which represents the consonant triads.

FIGURE 1 - The family of parsimonious transformations between consonant triads applied to the C-Minor chord: L (leading), P (parallel) and R (relative) relations (COHN, 1997, p. 2).

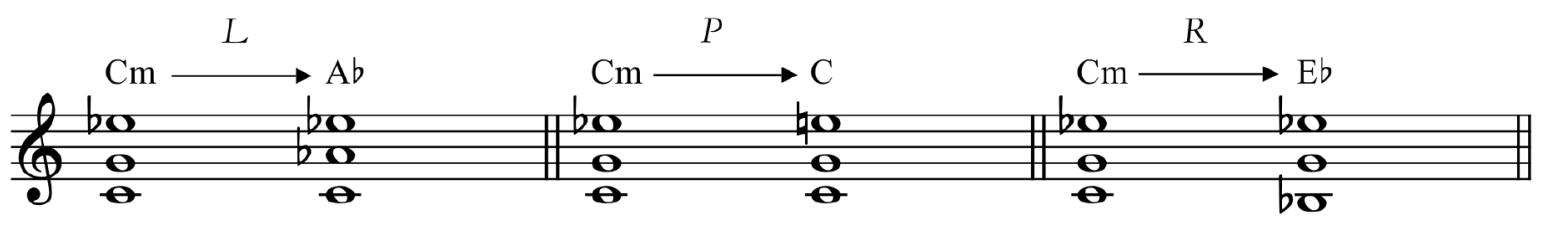

These parsimonious relations between chords or sets are represented by graphs, which is an essential aspect of the neo-Riemannian theory.

From a theoretical point of view, parsimonious graphs provide a visual representation of group actions on families of chords. This can prove useful to those who have a limited background in group theory as well as those whose background is more extensive. For those with a limited background, these graphs offer a convenient way of seeing (literally) parsimonious organization within families of chords, thus providing an intuitive sense of the complexities of group actions on these families. For those with a more extensive background, parsimonious graphs can provide a way of discovering relationships between group structures and families of chords. (DOUTHETT and STEINBACH, 1998)

Carlos Almada (2008), based on David Kopp’s “system formed by 13 classes of operations (...) which exhaust the possibilities of connections between triads with common notes” (p. 2), developed vector representations that formalize triad transformations, enabling computational analyses based on neo-Riemannian approach. In a computational program implemented in Matlab, "vector $\mathrm{K}$ is employed for determining which is the operation that connects each couple of triads entered as input” (p. 9); vector G is used for the production of graphs based on trajectories of the Tonnetz (see COHN, 1997). 
Based on the exhaustive list of relationships between elements in a given field, some authors proposed a similar approach in recent years but applied to the musical texture.

The starting point is the work of Wallace Berry (1976, p. 184-199). He proposes vertical groupings' formalization following varied criteria, such as the coincidence between points of attack, durations, and voice leading movements. In this proposal, Berry graphs these configurations as stacked numbers, which represents the textural configurations. We will call this approach here as Textural Analysis. In three separate papers, Pauxy Gentil-Nunes (2006, 2014, and 2018) evaluates in detail some relevant to the present study issues raised by Berry's approach.

These three texts also elucidate the critical differences in approach between Textural Analysis and Partitional Analysis (PA - GENTIL-NUNES, 2009). Among the distinctions, PA provides an exhaustive assessment of the adjacencies between the textural configurations (now treated as partitions). This proposal leads to the formulation of a general map of vertical grouping possibilities, now departing from any arbitrary criterion, which can be either the one already presented by Berry or any other proposed by the composer or analyst. Their inclusion relations are classified then as operators, of which the main ones are resizing $(\boldsymbol{m})$, revariance $(\boldsymbol{v})$, and transference $(\boldsymbol{t})$ :

1. Resizing $(\boldsymbol{m})$ is the relation between two partitions in which one part has a unitary difference in thickness, all other parts being identical. This is the case, for example, between [1,2] and $[1,3]$, or $[1,1,2]$ and $[1,1,1]$. When inserted in a temporal context, it is called positive $(\boldsymbol{m}+)$ or negative ( $\boldsymbol{m}$-), according to the successive addition or suppression.

2. Revariance $(\boldsymbol{v})$ is the relation between two partitions in which the number of parts has a unitary difference, caused by a distinct unitary part. This is the case, for example, between $[1,2]$ and $[1,1,2]$, or $[1,1,1]$ and $[1,1]$. When inserted in a temporal context, it is called positive $(\boldsymbol{v}+)$ or negative $(\boldsymbol{v}-)$, according to the successive addition or suppression.

3. Transfer $(\boldsymbol{t})$, on the other hand, is a composite relation between two partitions, which exhibit a resizing and a revariance between them, but in opposite directions $(\boldsymbol{m}+\boldsymbol{a n d} \boldsymbol{v}$ - or $\boldsymbol{m}$ and $\boldsymbol{v}+$ ). These combinations can be understood as a transfer of a unit from within a part to a new distinct unit part or vice versa - for example, [5] and [1,4] or [1,1,1] and [1,2]. When inserted in a temporal context, it is called positive $(\boldsymbol{t}+)$ or negative $(\boldsymbol{t}-)$, according to the unit 
part's successive dismemberment or absorption. The transfer quality grows toward the most dispersed (polyphonic) partitions.

Resizing, revariance, and transfer are adjacency relations between partitions (that is, relations where there is no possibility to find intermediate elements). Inserted in the temporal flow, they form leading structures, which can be used by the composer to create connections or disruptions, in the same way as the voice leading. These relations' exhaustive taxonomy form networks that express the possibilities of parsimonious movements or gaps between textural configurations. Three nets are formed by resizing, revariance, and transfer: respectively, mnet (Figure 2a), vnet (Figure $2 \mathrm{~b}$ ), and tnet (Figure 2c). We can plot each textural configuration by counting all the binary relations between its components and classifying them according to its collaboration or contraposition nature. From this operation, two indices emerge in each textural configuration: the agglomeration and dispersion indices. They are then used to locate each specific configuration in this phase space, covering all possible states of a given instrumental setting. This exhaustive taxonomy defines the lexical set of textural configurations, or, for short, lexset (for instance, the string quartet has lexset 8 , considering double stops; the guitar has lexset 6; in the examples of Figure 2, there are 9 presumed sound sources, e. g., lexset 9).

FIGURE 2 - The three primary nets between textural configurations: a) mnet; b) vnet; and c) tnet in the partitiogram (in this case, lexset $=9$ ). The union of these nets forms the background structure $(\mathrm{d})$ from which the analyst or composer can assess the trajectories and patterns delineated in musical works (see GENTIL-NUNES, 2017).

a)

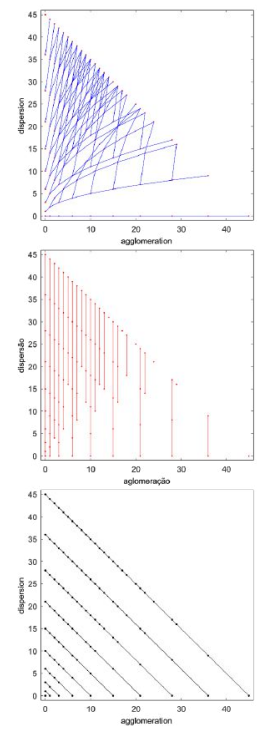

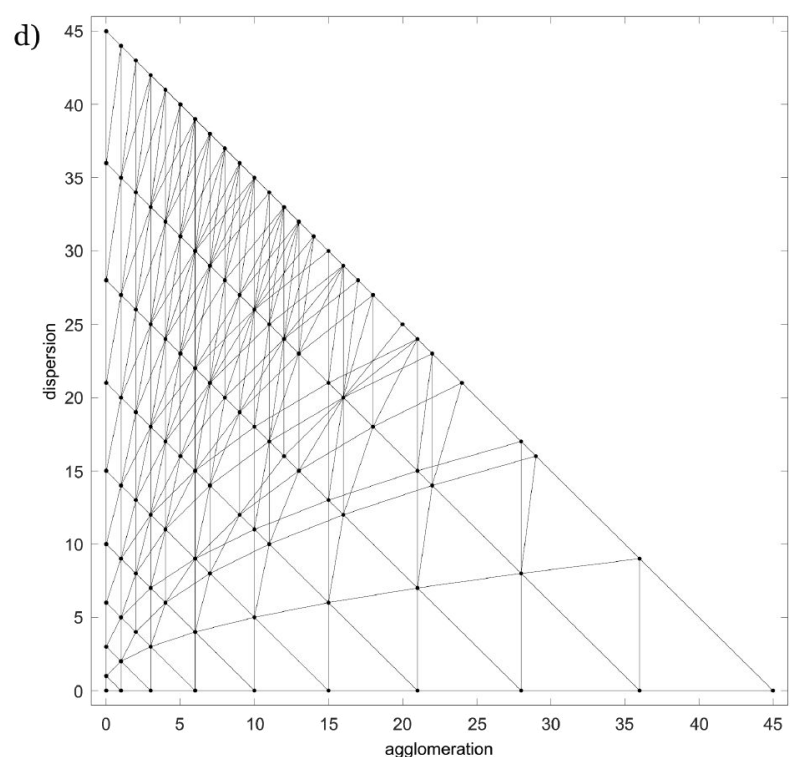


The union of these three primary networks (mnet, vnet, and tnet) provides a general map of the adjacencies between vertical groupings in general (Figure $2 \mathrm{~d}$ ). The analysis of the trajectories and patterns that appear on this map departing from musical works is one of the analytical methods used in Partitional Analysis. This graph, where the coordinates are the agglomeration and dispersion indices, and the adjacency relations are evaluated in this network of discrete points, referring to partitions, is called a partitiogram.

The composer or creator can apply these configurations to several musical fields or even extramusical ones. For example, he can drive the rhythmic texture (grouping through vertical comparison between attacks and durations of simultaneous parts) but also timbre, melodic texture, spatialization, choreography, or narrative structures, among other fields. This feature also means that fields with remarkable differences in its sensitive nature can acquire automatic and reciprocal isomorphism, which can be very useful for converting one surface to another or generating different surfaces from a single structural sequence of textural configurations. Gentil-Nunes (2017, p. 116-117) gives some examples of this possibility at the elementary level.

Didier Guigue, for example, has developed some algorithms using PA as a basis for assessing orchestral amalgamations and fissures in Webern's Variations Op. 30, for orchestra, and applying the concept of partition to the grouping of instrumental colors, what he calls as instrumental partitioning.

In terms of orchestral writing, Webern is known for his economy and pointillism, which
our analysis highlighted. The expectation, then, is to be, in most of the time, in front of
fine and transparent textures. (...) To support this hypothesis, we developed an algorithm,
Relative Voicing Complexity (RVC), based on Partitional Analysis, a theory proposed by
Pauxy Gentil-Nunes ([5]), which refines the methodological proposal of Wallace Berry
([2], p. 184). The more the instrumental parts are agglomerated - that is, the more they
form homophony and/or homorhythmy - the more the texture becomes "simpler", and
the reverse when dispersed. (...) line ((Partition) (crit.)), shows the format we use so that
the parsing analysis is intelligible for OpenMusic and SOAL, encoded in Common Lisp.
(GUIGUE, 2018, p. 125)

A similar approach was used by Thiago Cabral Carvalho (2017, p. 184) to analyze the orchestration of Hermeto Pascoal's Sinfonia in Comics. Through the partitional analysis carried out using the Parsemat $^{\circledast}$ software (GENTIL-NUNES, 2004), Thiago selects the sections of the work in which there are more significant instrumental heterogeneity and greater timbre diversity (Figure 3). 
On the poietic side, Liduino Pitombeira (2017) provides a remarkable example of compositional planning based on the extraction and systemic modeling of structures of the partitiogram. The relations between the rhythmic partitions of an excerpt of Ponteio $n^{\circ} 3$, by Camargo Guarnieri (Table 1), serve as part of a model for the compositional design of an original Pitombeira's piece called Tejido.

FIGURE 3 - Identification of the sections with higher instrumental complexity in Hermeto Pascoal's Sinfonia in Comics (CARVALHO, 2017, p. 184) using Parsemat ${ }^{\circledR}$ software (GENTIL-NUNES, 2004).

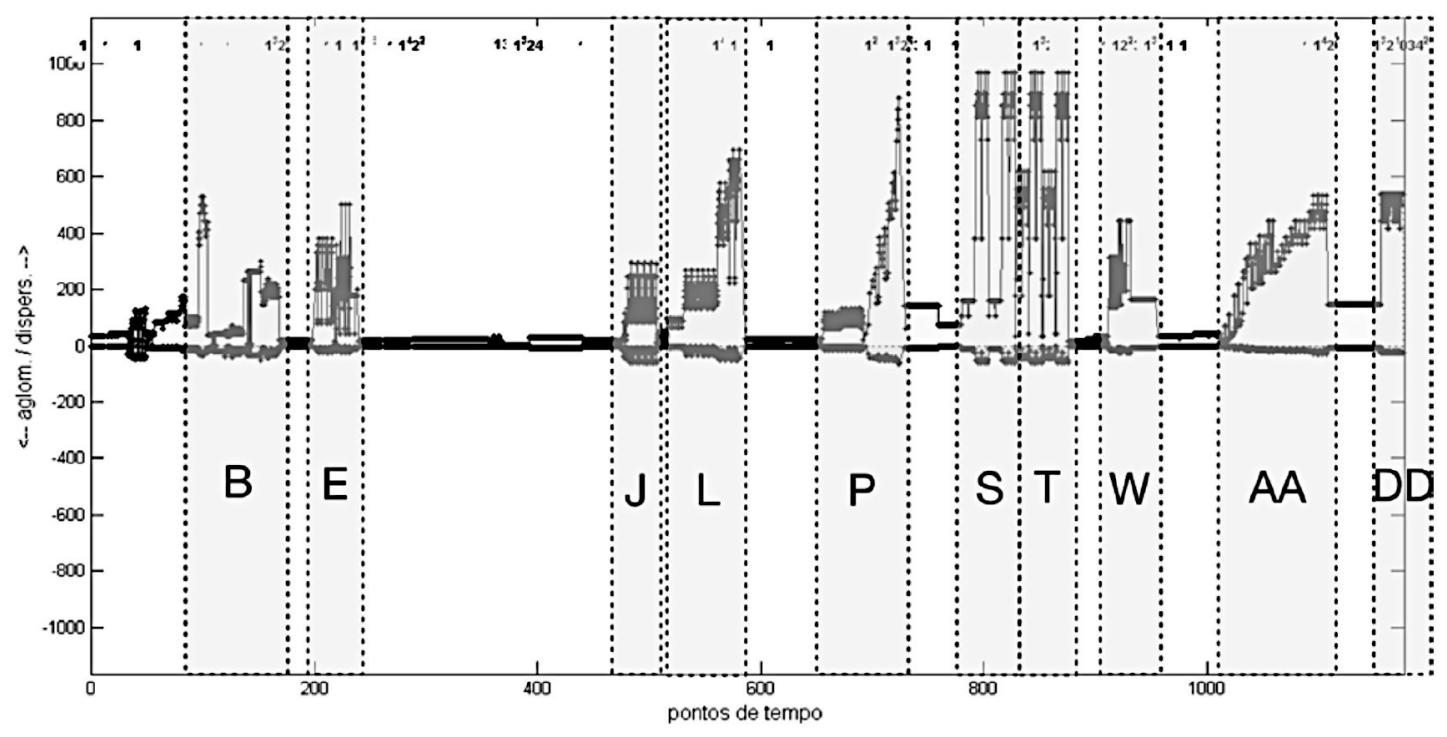

On the other hand, Daniel Moreira (2019) expanded the applications of PA to the various tasks of the composer during his creative process. Several examples of applications to timbre, articulation, contour, voice leading, among others, are presented, generating a series of innovative concepts and tools for the constitution of a new field called Textural Design.

One of the most recent applications of Partitional Analysis comes from the observation of how texture conditions certain types of couplings between instruments and the bodies of performers. This application is called here as performative partitioning. This type of research arises as a natural consequence of the focus on texture, which emerges from a centrifugal movement from the musical structure to the musical surface. Much of the relations between partitions results from interactions that occur at an even more superficial level, between instrumental combinations and their techniques. From this observation, some researchers of PA have developed new concepts and tools 
covering more specific fields, such as the textural issues arisen by the composition of solo pieces for guitar (RAMOS, 2017), monophonic instruments (GENTIL-NUNES, 2016), and piano (MORAES, 2020). Daniel Moreira's work (2019) also falls within this scope by focusing on AP's applications to the compositional process.

TABLE 1 - Consecutive rhythmic partitions and their relations in mnet, vnet and tnet networks in the initial section of Ponteio $n^{\circ}$ 3, by Camargo Guarnieri (adapted from PITOMBEIRA, 2017, p. 10).

\begin{tabular}{ccc}
\hline Bar number & Partition & Relation with next partition \\
\hline 0 & {$[1]$} & $2^{*} \mathrm{v}$ \\
\hline $1-3$ & {$[1,1,1]$} & $2^{*} \mathrm{~m}$ \\
\hline 3 & {$[1,1,3]$} & $2^{*} \mathrm{t}$ \\
\hline & {$[1,1,1,3]$} & $-2^{*} \mathrm{t}$ \\
\hline & {$[1,1,3]$} & $2^{*} \mathrm{t}$ \\
\hline 4 & {$[1,1,1,3]$} & $-\mathrm{m}$ and $-\mathrm{v}$ \\
\hline & {$[1,1,1]$} & $2^{*} \mathrm{~m}$ \\
\hline & {$[1,1,3]$} & $2^{*} \mathrm{t}$ \\
\hline 5 & {$[1,1,1,3]$} & $-2^{*} \mathrm{t}$ \\
\hline & {$[1,1,3]$} & $2^{*} \mathrm{t}$ \\
\hline
\end{tabular}

\section{Guitar textures and the emergence of Guitar Textural Proposal (GTP)}

Fabio Adour (1999), when thinking about guitar composition, does it from the point of view of texture. Adour divided the research by traditional textural categories - monophony, homophony, polyphony, etc. In each section, Adour meticulously described the technical implications of implementing these textural categories on the guitar. For instance, in the polyphony section, the author presents a progressive approach, from two voice-leading with a passive one (a pedal as limit) to four-voice polyphonic structuration (which is challenging to play and rare in the guitar repertoire). He analyzes the technical problems and proposes compositional solutions. The idiomatic guitar textures - blocks, arpeggios, broken chords, etc. - are also described and analyzed. In short, Adour's 
work intends to be a supplement for the poor informational material in the instrumentation literature about composition for guitar:

Helping to enrich the sound palette available to those who write music is always an extremely urgent and useful task. As far as we are concerned, we will use every effort to fill a specific gap: information about the guitar. Insufficient publications on the instrument, in fact, have inhibited many composers from writing for it; some do not even consider the possibility of taking advantage of its unique sound. On the other hand, those who try to use it are either guitarists, or do not explore its various possibilities, or try to obtain information directly from the interpreters. (ADOUR, 1999, p. 2.)

Adour was aware of the insufficiency related to the traditional approach of the textural parameter:

\begin{abstract}
What is it, anyway? Accompanied double melody, characterizing a variant of the homophonic texture? Counterpoint with accompaniment, characterizing a variant of the polyphonic texture? Or just one of the textural possibilities that academic classifications fail to address? For us, it does not imply to point out new and supposedly sufficient categories; we just should notice the insufficiency of the traditional ones, as they cannot limit our work. Therefore, we will use them very freely, allowing us to expand their concepts to the maximum, always with well-defined purposes (p. 11).
\end{abstract}

Focused on the performance aspects, Sérgio Freire and Pedro Cambraia (2015) also work from a textural perspective, aiming to produce information about how performers play basic textures founded on guitar repertoire. They take as objects of analysis performances of excerpts extracted from pieces that are remarkable examples of specific configurations, namely two-voice polyphony on Bach's Bourrée (from the Suite for Lute in E-minor); choral texture on Brouwer's Etude 2; arpeggios on Villa-Lobos's Etude no. 1; and fast tempo monophony on Brouwer's Etude 7. Electronic pickups applied on a guitar and connected to a computer provides information. The note event, defined by some parameters, is the focus of low-level descriptors. The list of these variables includes event number; time of the event (onset or offset); the number of the string in use; fundamental frequency; amplitude; spectral centroid; slur flag; the presence of bend or vibrato (op. cit., p. 1-2). The mid-level descriptors, directed for excerpts analysis, are divided into six categories: global, guitar-specific, rhythm, pitch, amplitude, and spectrum descriptors. Based on these tools, they present a study of five excerpts and discuss the advantages and difficulties of this method. This work is an example of the concern with the relationship between texture and technique in the guitar field. 
The Guitar Texture Analysis (RAMOS, 2017) is an analytical tool devised for the guitar repertoire that deals with relations between the textural aspect and the instrumental performance's technical resources. Here we read texture departing from Rhythmic Partitioning Analysis (see GENTIL-NUNES, 2009，2017，2018), in which integer partitions represent the textural configurations. One of this approach's applications was already realized on Leo Brouwer's Étude Simples series (1972; for the analyses, see RAMOS, 2017, p. 51-99). Ramos individually analyzed all the 20 pieces and has done comparative studies. Between the results achieved, Ramos observed the most used textural configuration by Brouwer in the Etudes. This result is the starting point of the present work, as will be discussed below.

As a first step, we will consider the following basic elements, which can be found on Etude No. 14 (BROUWER, 1972, Figure 4).

a) Blocks: groups of notes with coincident attacks and the same duration (Figure 4a), considering the number of simultaneous notes. In the case of blocks with two sounds, the structure is represented by the number [2];

b) lines: rhythmically independent notes or sequences (Figure 4b), each represented by the number [1].

Isolated and overlapping occurrences of such elements in the example in question (Figure 4) are represented by the partitions [1], [1,2], and [1,1,2].

FIGURE 4 - Etude 14, excerpt (BROUWER, 1972, c. 31-33). Unitary parts (letters $b$ ) and two-note blocks (letter $a$ ). The color bars illustrate the juxtaposition of the simultaneous parts, generating the partitions [1], [1,2], and $[1,1,2]$.

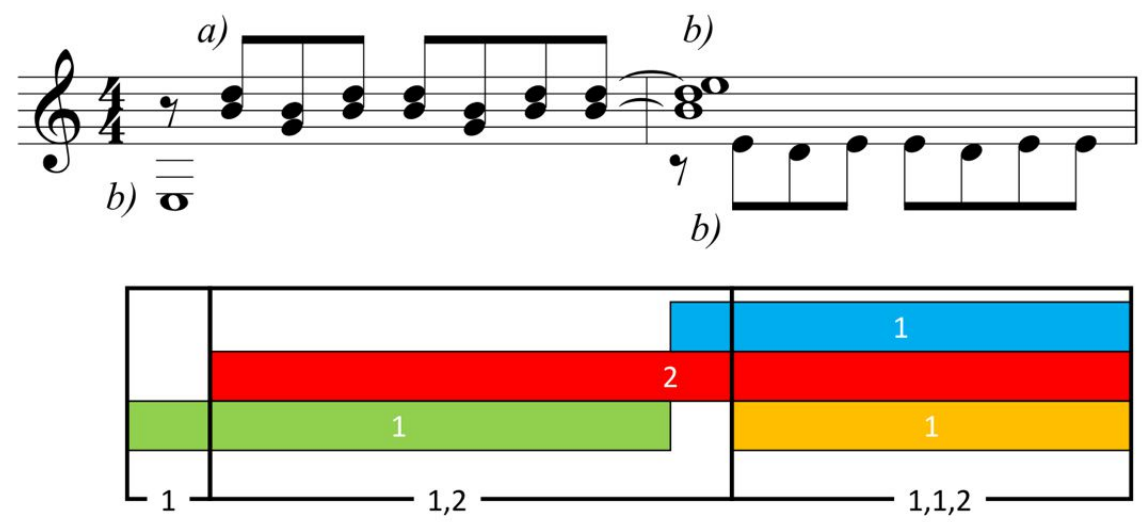


FIGURE 5 - a) Etude No. 1, excerpt (BROUWER, 1972, c. 1-2). ${ }^{2}$ b) Diagram of its GTP. The letters in italics indicate the fingers of the right hand that articulate the parts nearby. ${ }^{3}$ The numeral [0] on the upper left side of part [2] indicates that the part is performed using notes located on open strings. ${ }^{4}$

b)

a)
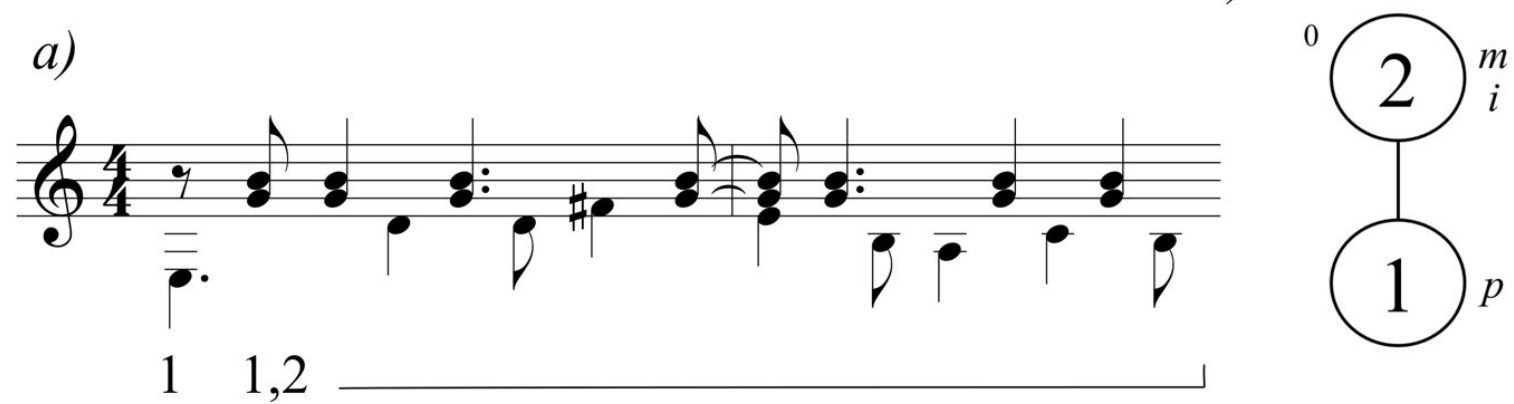

Among the structures observed by the Rhythmic Partitioning Analysis, one or a small set of partitions can represent the global textural structure of the piece (see RAMOS, 2017) or the excerpt in question, thus defining its Textural Proposal. For example, Etude No. 1 (BROUWER, 1972; Figure 5) consists of a bass line accompanied by two-note blocks, generating three partitions: [1], [2] (this one with very residual occurrences), and $[1,2]$. The latter predominates in terms of global duration, with a large difference in relation to the others (Figure 6). Also, partitions [1] and [2] are exclusively the result of eventual part silences, which creates then the subpartitions of the main partition [1,2] (see RAMOS, 2017; GENTIL-NUNES \& RAMOS, 2018). We said that, in this case, the partition [1,2] is the Textural Proposal of Etude No. 1. In this sense, the Textural Proposal constitutes a referential configuration that prevails and characterizes the piece's main textural mode.

\footnotetext{
${ }^{2}$ Transcribed using an alternative note grouping for illustrative purpose.

${ }^{3}$ In guitar writing, the fingers of the right hand are traditionally represented by the letters $p$ (thumb), $i$ (forefinger), $m$ (medium), a (ring).

${ }^{4}$ Partition [2], although not occurring in the selected fragment (c. 1-2), occurs sporadically on the piece (see Figure 6 and RAMOS, 2017).
} 
FIGURE 6 - Sum of the durations relative to the occurrences of the partitions contained in Etude No. 1 ([1,2], [1] and [2]), measured in time units.

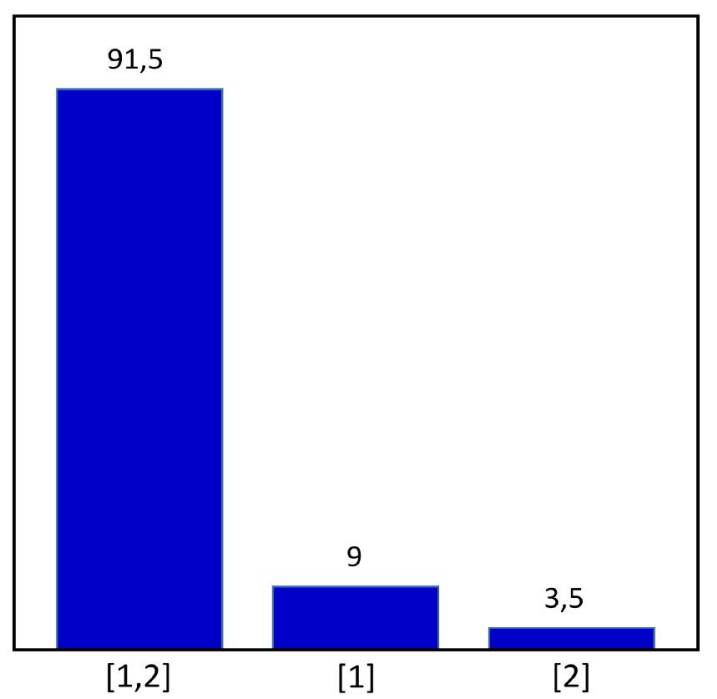

If there are any behavior patterns in the use of technical procedures - fingering of both hands, use of open strings, simple or composite slurs, etc. - indicated or suggested on the score, they are associated with the previously determined textural proposal. For example, in Etude No. 1 (Figure 5a), the bass line (part [1]) is performed exclusively with the finger $p$. In contrast, in the upper accompaniment (part [2]), a static behavior predominates - an articulation of blocks formed by two notes (Sol2 and Si2) located on open strings, performed with the fingers $i$ and $m$. This analytical procedure is called Guitar Textural Proposal (GTP), represented by a diagram (Figure 5b). The parts are indicated within circles and arranged vertically, reproducing its register placement. Technical elements of the right hand are shown on the right side of the chart, and, on the left side, left-hand procedures. The GTP diagram is useful for formalizing the instrument's technical uses, guiding musical analysis, and being used as a tool for compositional design (RAMOS, 2017).

In Rhythmic Partitioning, as we see before, there are relations between partitions that define parsimonious movements or transformations between configurations. On the other hand, when working on the instrumental uses of the guitar, it seems to be a more complex task to make such a definition. This situation occurs because of the large number of technical variables involved in the very act of playing the guitar. Moreover, such variables do not belong to the field of traditional musical structure, leading the analytical work to embrace its connection with the scope of instrumental techniques and vocabulary. 
The present work is an investigation of the possibility of determining parsimonious transformations in GTPs. As the material for a case study, each piece of the Etude Simple series (BROUWER, 1972) was previously analyzed (see RAMOS, 2017). Seeking to establish a suitable research field, we delimit the present work to pieces of the series with the partition $[1,2]$ as referential. This partition is the most widely used in the Etudes, generating a considerable diversity of GTPs.

This work's specific goal is to establish an ordering of the GTPs related to the selected repertoire in an increasing scale of complexity, trying to possibly establish a parsimonious variation net that connects such structures.

\section{Plotting a GTP parsimonious variation net}

The GTP of Etude No. 1 represents the simplest structure inside the progressive scale of complexity, considering the scope of the present paper (GTPs based on partition [1,2]). In this case, the GTP is formed by a bass line (part [1]) and a static accompaniment (part [2]), the latter composed by a pair of notes located on open strings, resulting in the textural proposal [1,2] (see Figure 5a). In a hypothetical exercise of performing a parsimonious recessive movement, that is, slightly reducing the GTP complexity in question, just one alternative would be available.

FIGURE 7 - a) Etude No. 4, excerpt (BROUWER, 1972, c.4-10). b) GTP diagram of the piece. The right-hand fingering pattern is indicated in italics.

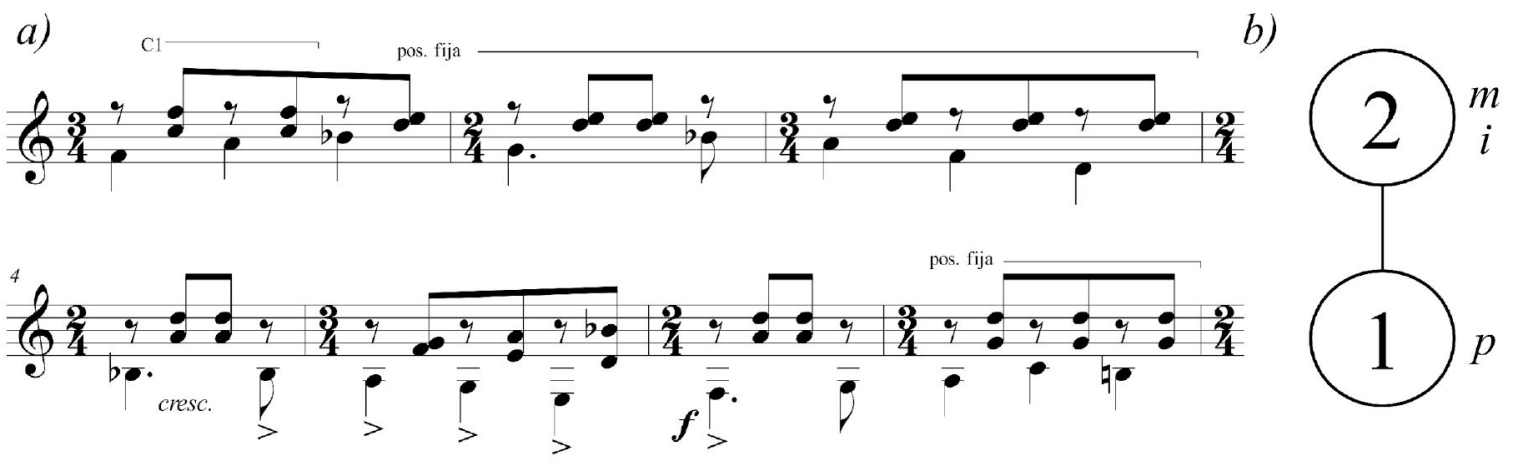

Negative resizing or revariance would lead only to GTPs outside the realm of [1,2], which would be beyond the scope of this paper.

Simplification in the technical parameters by itself would not be feasible either: the 
accompaniment (part [2]) already represents the floor of such complexity by not requiring any action but that of the right hand. In turn, the bassline (part [1]) could be reduced in complexity, becoming static, for example, as is the accompaniment. In this way, we only could have a structure composed of bassline and accompaniment, both in open strings, which does not occur in Brouwer's Etudes.

The next element of this progression must be a parsimoniously more complex GTP than that found in Etude No. 1. For example, part [2] could acquire linear motion, requiring the left hand's use. This situation, which happens sparsely in Etude No. 1, is, in fact, the structural behavior of Etude No. 4 (Figure 7).

FIGURE 8 - Example of a structure formed by partition [1,2], whose upper register part - two-tone blocks (part [2]) is performed using the third string (Sol3) open and pressed notes on the second string - Re3, Re\#3, and Mi3, located on the frets 3, 4 and 5, respectively. Original concept of the present authors.

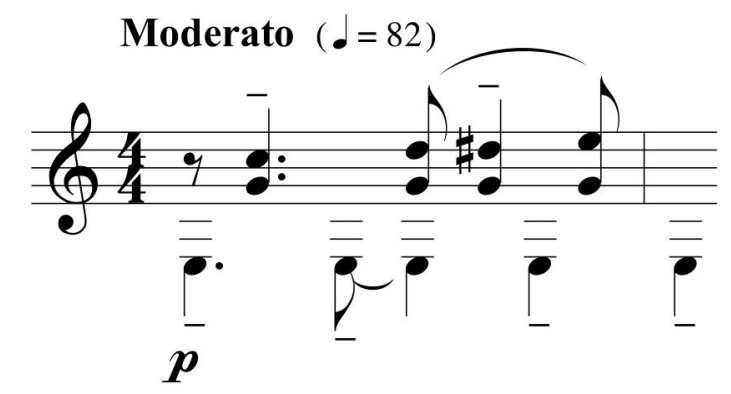

Using a strict criterion, there would be an intermediate step between the two quoted configurations: the linear movement of one of the accompaniment notes (part [2]), keeping the second note as a pedal, located in an open string. For example, we can observe the sequence Sol2Do3, Sol2-Re3, Sol2-Re\#3, Sol2-Mi3, in which Sol2 is located on the third string (Figure 8). However, one more time, this is a procedure not found within the repertoire in question. A further step towards increasing technical complexity would be applying slurs in the execution of one of the parts, which is not the case in Etudes 1 and 4. The most straightforward alternative would be to proceed with such an application to the melodic element - the bass line (part [1]). Accompaniment would require more complex procedures - simultaneous slurs - because it is composed of blocks of two sounds (part [2]). In fact, Brouwer takes the second option in Etude No. 13 (Figure 9). If, on the one hand, it represents a gap relative to previous configurations in our conceptual framework, on the other, the use of the resource is carried out in a considerably uniform and simplified way: employing 
only the ascending slurs. Moreover, such actions start exclusively from a pair of notes located on open strings, significantly reducing the left hand's tension.

The GTP of Etude No. 14 (Figure 10) is precisely a variation of that found in Etude No. 13, in which the scope of possibilities is expanded, including descending slurs and those with initial and final notes located on pressed strings.

FIGURE 9 - a) Etude No. 13, excerpt (BROUWER, 1972, c. 1-4): the articulation of the part [2] using simultaneous slurs originating from open strings (III and IV, in this case); b) GTP diagram for Etude No. 13: zeros represent notes on open strings, $x$ and $y$ refer to notes on pressed strings.

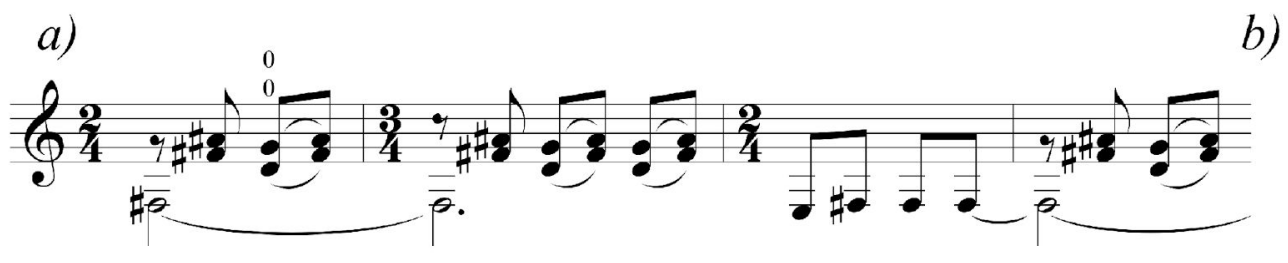

b)

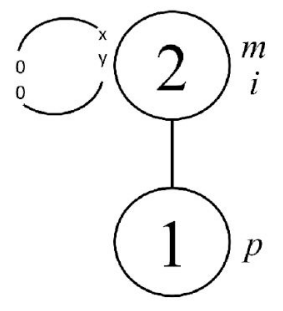

FIGURE 10 - a) Etude No. 14, excerpt (BROUWER, 1972, c. 20-23): use of simultaneous ascending and descending slurs, including pressed notes as the origin of gestures. b) GTP diagram for Etude No. 14: the letters $x$ and $z$ represent source notes of the slurs, $y$, and $\mathrm{w}$ describe the arrival notes.

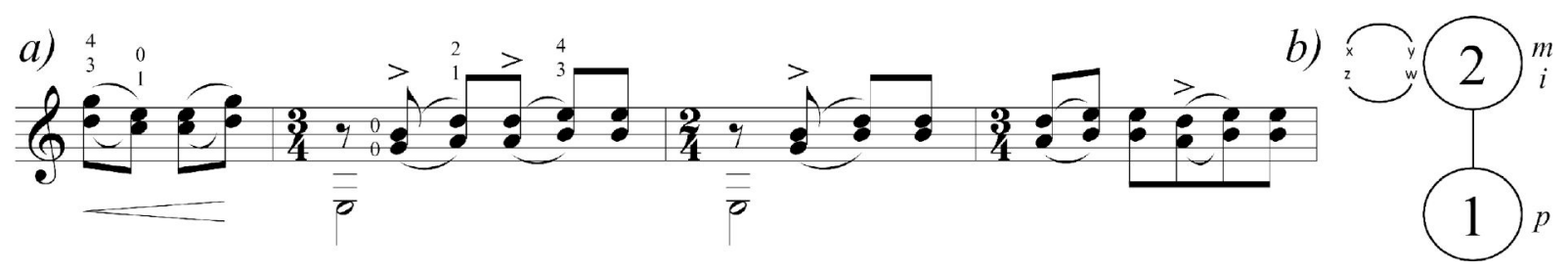

Etude No. 15 presents a considerably more complex formal structure than those found in the pieces analyzed so far, also showing a wider textural variety. Among the GTPs found, two belong to the partition [1,2]. The first one is articulating the element on the upper register (part [2]) in FPA In the context of Guitar Textural Analysis, the articulation of a chord in FPA is interpreted as a derived form of a block (see RAMOS, 2017). For the analysis, we transcribed the FPAs in the GTP diagram as blocks. We signal the operation by a qualitative indication of this specificity, in the form

\footnotetext{
${ }^{5}$ FPAs: Fixed Position Arpeggios. It consists of sequential execution of notes of a massive structure (block). It differs from the simple (monophonic) arpeggio by the obligatory location of notes in distinct strings, so that each note will continue to sound over the following ones (see more details in RAMOS, 2017). In the tradition of classical guitar, the term arpeggio often refers to FPAs.
} 
of an arpeggio line (Figure 11). In fact, the GTP of Etude No. 15 is not a new element of the ongoing sequence. Left-hand procedures in Etudes 13 and 14 produce variations in part [2] - the slurs. Changes in the right-hand behavior in Etude No. 15, on the other hand, generate the variation expressed in the execution of the blocks in FPA. Therefore, this configuration sets a bifurcation in the overall structure of GTPs, ahead of our pathway.

Another situation in Etude No. 15 establishes a transformation not yet addressed - the register inversion of parts (Figure 12). In this excerpt, both elements work without any of the resources found in Etudes 13 and 14; however, part [2] is at the lower register, while part [1], previously positioned as the bassline, is in the upper register. Thus, a new branch germinates at the second node of the net, next to the GTP of Etude No. 4 (see Figure 13). Hence, a new question arises: which GTP is more elementary concerning the guitar vocabulary? The answer lies in the guitar idiomatism: the organization found in the former GTPs. The bassline against upper blocks implies a right-hand gesture. The thumb ( $p$ finger) acts in rhythmic alternation with the simultaneous action of the other fingers - index and middle ( $i$ e $m$ ), changing to index and ring fingers $(i$ e $a)$ in some cases. Basslineblock textural configuration is a traditional accompaniment pattern, not only for the guitar. Moreover, the thumb's anatomic opposition to the other fingers is an essential factor favoring the two elements' rhythmic alternation.

FIGURE 11 - Etude No. 15 (BROUWER, 1972, c. 18-21), excerpt. a) original notation (simplified for illustration purpose); b) transcription with FPAs rewritten as blocks and the GTP diagram of the example. The wavy line on the right side of the part [2] indicates the FPA arpeggio pattern.

a)

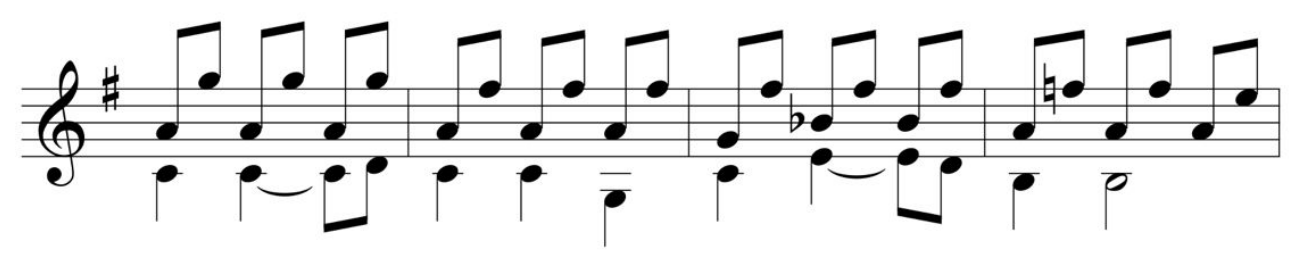

b)
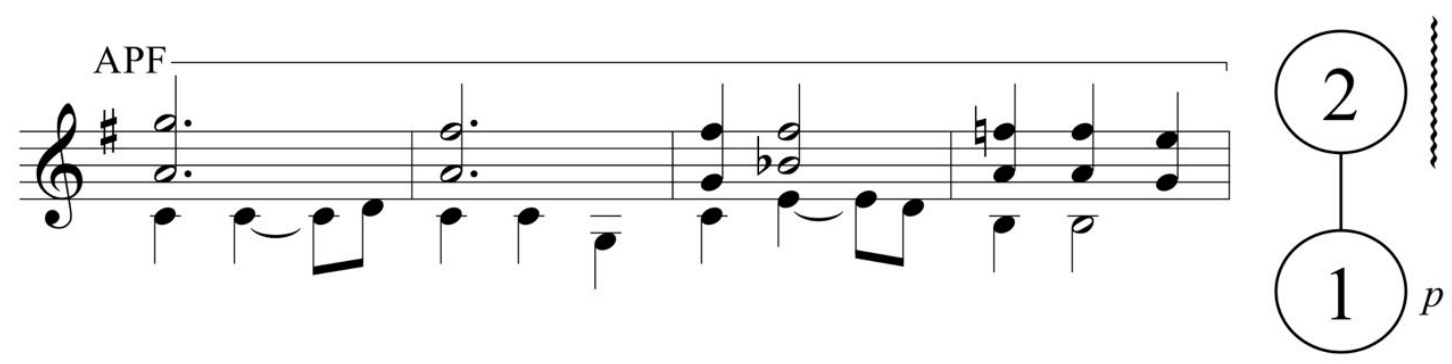
FIGURE 12 - a) Etude No. 15 (BROUWER, 1972, c. 42-57) excerpt. b) GTP of the example. Part [2] is in the lower register, with right hand fingering in italics.

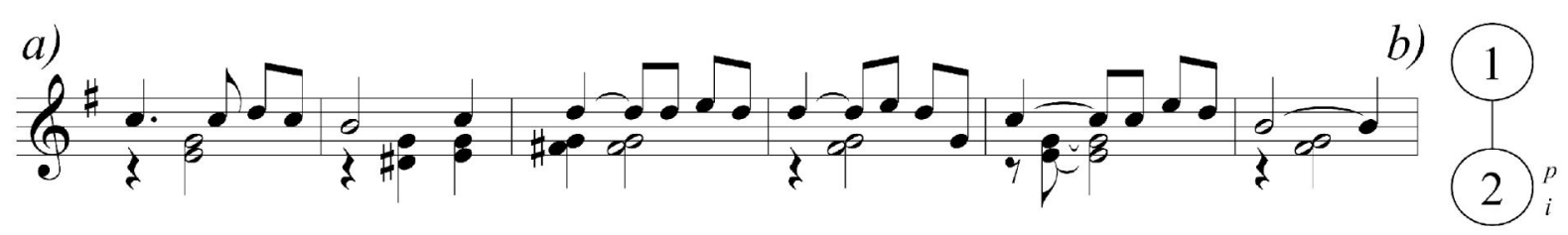

With all GTPs constituted by partition [1,2] addressed, it is possible to reconstitute the overall outline made by the present work (Figure 13):

1. Variation by assigning linear motion to static element performed on open strings, requiring pressed ones. (Figure 13a).

2. Variations by left-handed procedures (Figure 13b): application of ascending followed by ascending and descending slurs.

3. Variations by right-hand procedures (Figure 13c): blocks presented as FPAs.

4. Variation by inverting register between parts: Part [2] of partition [1,2] assumes the lower register, while [1] takes the upper one (Figure 13d).

FIGURE 13 - Etudes 1, 4, 13, 14, and 15: net of parsimonious variations in the scope of GTPs formed by partition $[1,2]$. a) assignment of linear motion to one part; b) left-hand procedures (ascending and descending slurs); c) righthand procedures (FPA); d) inversion of register between parts.

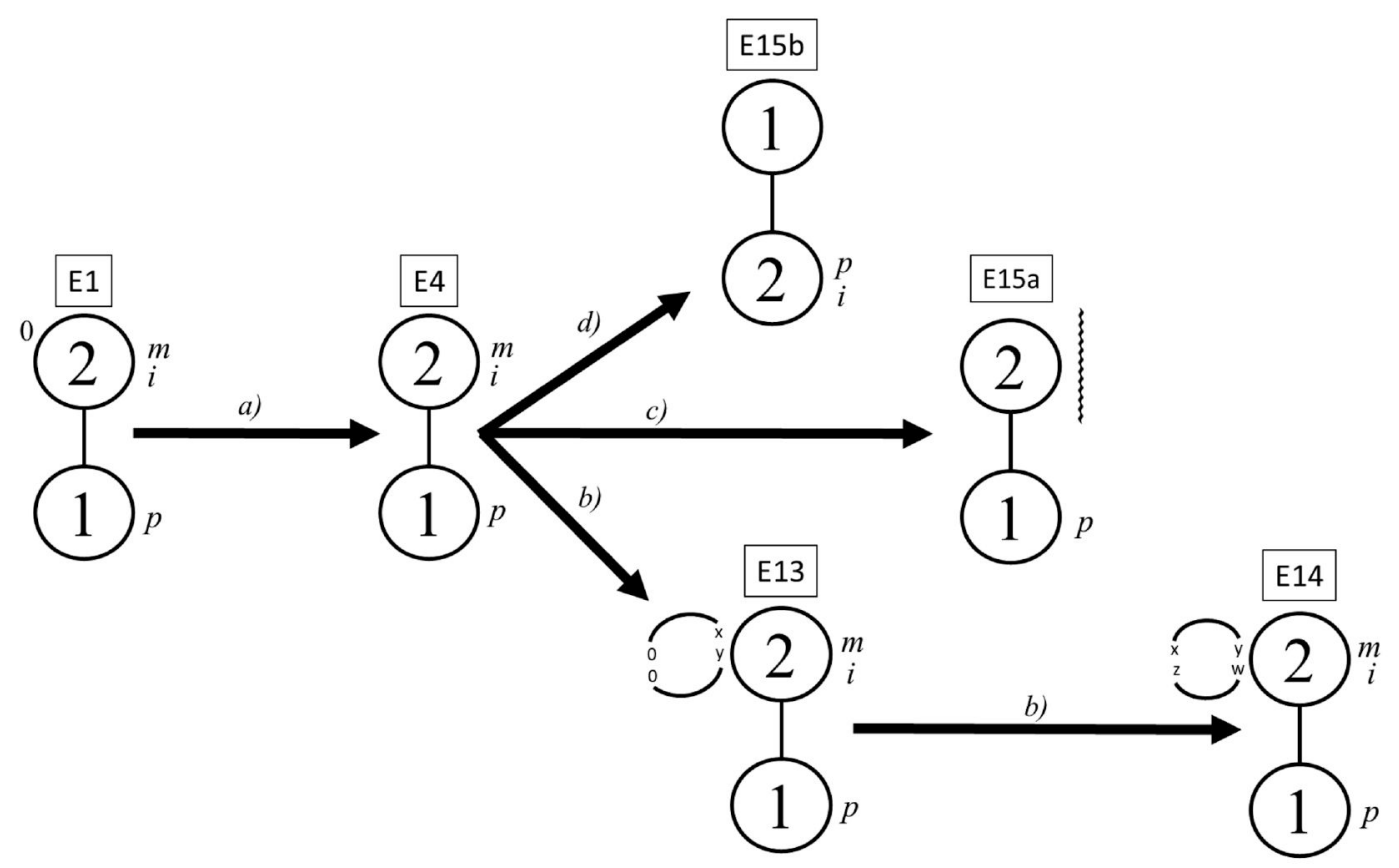




\section{Conclusions}

Brouwer's Etudes Simples are part of the canonical repertoire of the concert guitar. The instrumentalist and analyst, working on the complete series, are introduced to a vast vocabulary of techniques and textures (see analysis of the 20 pieces in RAMOS, 2017). By delimiting the observation field using only GTPs [1,2], it is possible to compose a net of parsimonious relations, based on the elementary technical and textural structure of Etude No. 1. In some cases, we suggest hypothetical intermediate structures that have to fill in adjacencies not occupied by the GTPs used in Brouwer's studies. The overall resulting structure is not linear but branched: the high number of parameters considered in the formation of GTPs causes several bifurcations (see Figure 13). Texture and performativity interlace themselves in the guitar score's realm. This interaction leads to a view where the limit between structural and performative aspects is blurred. In the present authors' view, this patchwork can bring some remarkable insights into the analysis and performance of guitar works.

\section{REFERENCES}

ADLER, Samuel. The study of orchestration. Nova Iorque: W. W. Norton \& Company, 2002. ADOUR, Fábio. Sobre a Composição para o Violão. Dissertação (Mestrado em Música). Centro de Letras e Artes, Universidade Federal do Rio de Janeiro. Rio de Janeiro, 1999

ALMADA, Carlos de Lemos. Vector Representation of Triadic Transformations. Per Musi, Belo horizonte: UFMG. No. 38, p. 1-12, 2018.

ANDREWS, George. The Theory of Partitions. Cambridge: Cambridge University, 1984.

BERRY, Wallace. Structural Functions in Music. NewYork: Dover, 1976

BROUWER, Leo. Estudios Sencillos. Paris: Editions Max Eschig, 1972. Score. Guitar.

CARVALHO, Tiago Cabral. (2017). Por um modelo morfológico aplicado à análise musical: investigando processos criativos na Sinfonia em Quadrinhos de Hermeto Pascoal. Tese de Doutorado. João Pessoa: Universidade Federal da Paraíba.

COHN, Richard. Neo-Riemannian Operations, Parsimonious Trichords, and Their "Tonnetz" Representations. Journal of Music Theory, Vol. 41, No. 1, (Spring,), 1-66, 1997.

COHN, Richard. Introduction to Neo-Riemannian Theory: A Survey and a Historical Perspective. Journal of Music Theory, Vol. 42, No. 2, Neo-Riemannian Theory (Autumn, 1998), pp. 167-180. 
COLLISON, Stephen. Grundgestalt, Developing Variation, and Motivic Processes in the Music of Arnold Schoenberg: An Analytical Study of the String Quartets. Thesis (PhD.). Londres: King's College, 1994.

DOUTHETT, Jack and STEINBACH, Peter. (1998). Parsimonious Graphs: A Study in Parsimony, Contextual Transformations, and Modes of Limited Transposition. Journal of Music Theory, n. 42, v. 2, p.241 - 263.

FRISCH, Walter. Brabms and the Principle of Developing Variation. Berkeley: University of California, 1984.

FREIRE, Sérgio; CAMBRAIA, P. Analysis of musical textures played on the guitar by means of real-time extraction of mid-level descriptors. 12th International Conference on Sound and Music Computing. Proceedings... Maynooth: Maynooth University, 2015. v. 1. p. 509-514.

GENTIL-NUNES, Pauxy. PARSEMAT - Parseme Toolbox Software Package. Rio de Janeiro: Pauxy Gentil-Nunes. 2004. Disponível em https://pauxy.net/parsemat-2/. Acesso em 01/11/2020.

Parsemas e o método de Fux. Revista Pesquisa e Música. Rio de Janeiro: Conservatório Brasileiro de Música, 2006, v. 1, p. 38-47.

. Análise particional: uma mediação entre análise textural e a teoria das partições. 2009.

Thesis (Doctor Degree, Music). Centro de Letras e Artes, Universidade Federal do Estado do Rio de Janeiro, Rio de Janeiro, 2009.

Formalização do espaço textural melódico em instrumentos monofônicos. XXVI Congresso da ANPPOM. Proceedings... Belo Horizonte: UFMG, 2016. Disponível em https://www.anppom.com.br/congressos/index.php/26anppom/bh2016/paper/download/4332/ 1373. Acesso em 02/11/2020.

Análise Particional e Análise Textural: uma abordagem cognitiva do Particionamento rítmico. $13^{\circ}$ Colóquio de Pesquisa do Programa de Pós-Graduação em Música da UFRJ. Proceedings... Rio de Janeiro: UFRJ, 2014, p. 79-86. Disponível em https://ppgm.musica.ufrj.br/analise-particional-e-analise-textural-uma-abordagem-cognitiva-doparticionamento-ritmico/. Acesso em 31/10/2020.

Partitiogram, mnet, vnet and tnet: Embedded abstractions inside compositional games. In: The Musical-Mathematical Mind:patterns and transformations. Berlin: Springer, 2017, p.111118.

Nesting and intersections between partitonal complexes. Musmat: Brazilian Journal of Music and Mathematics, vol. 2 \#1, p. 93-108, 2018.

GENTIL-NUNES, Pauxy e RAMOS, Bernardo. Complexos Particionais. National Congress of Music and Mathematics of UFRJ. Proceedings...Rio de Janeiro: UFRJ, 2018.

GUIGUE, Didier. The Function of Orchestration in Serial Music: The Case of Webern's Variations Op. 30 and a Proposal of Theoretical Analysis. MusMat-Brazilian Journal of Music and Mathematics, 2018, v. 2, no. 1, pp. 114-138.

HAIMO, Ethan. Atonality, Analysis, and the Intentional Fallacy. Music Theory Spectrum. vol. 18, number 2, p. 167-199, 1996. 
KOPP, David. Chromatic Transformations in Nineteenth-Century Music. New York: Cambridge University Press, 2002.

MORAES, Pedro Miguel. (2020). O corpo como fator de modelagem da textura pianística. III Congresso da Associação Brasileira de Teoria e Análise Musical (TeMA) \& IV Congresso Internacional de Música e Matemática. Proceedings... Rio de Janeiro: PPGM-UFRJ, 2020 (in press), pp. $1-26$.

MOREIRA, Daniel. Contornos musicais e textura: perspectivas para análise e composição. IV SIMPOM. Proceedings... Rio de Janeiro: UNIRIO, 2016.

MOREIRA, Daniel. Textural Design: a compositional theory for the organization of musical texture. Thesis (Doctor Degree, Music). Centro de Letras e Artes, Universidade Federal do Estado do Rio de Janeiro, Rio de Janeiro, 2019.

PISTON, Walter. Orchestration. London: Victor Gollancs LTD, 1969.

PITOMBEIRA, Liduino. Modelagem sistêmica como metodologia pré - composicional. XXVII Congresso da Associação Nacional de Pesquisa e Pós-Graduação em Música. Proceedings...

Campinas: UNICAMP, 2017, p. 1-19. Disponível em https://anppom.com.br/congressos/index.php/27anppom/cps2017/paper/viewFile/5096/1811. Acesso em 02/11/2020.

RAMOS, Bernardo. Análise de Textura Violonistica: teoria e aplicação. 2017. Dissertation (Master Degree, Music). Universidade Federal de Rio de Janeiro. Rio de Janeiro, 2017.

RIMSKY-KORSAKOV, Nicolay. Principles of orchestration. New York: Dover Publications, 1964.

\section{ABOUT THE AUTHORS}

Guitarist, composer, arranger. Bachelor's Degree in classical guitar, Master Degree in Composition and PhD student at the Federal University of Rio de Janeiro. Member of the research group MusMat. Continuous activity in the fields of Brazilian music and contemporary jazz. Rocinante Records' artist since 2019. First prize at the Guarulhos instrumental festival (2008). Participation as composer and guitarist in many albums, among them: Bamboo (Brasilianos, 2010) and Overture (2012) with Bamboo Group, Gesto (Spiral Music, Japan, 2016). Member of Idriss Boudrioua's Base and Brass since 2018. "Cangaço” (Rocinante Records, 2019) is his most recent work as leader. ORCID: https://orcid.org/00000002-0710-3745. E-mail: bernardo.ramos.br@gmail.com

Composer and flutist. Master Degree in Composition and Doctor Degree in Musical Language and Structure. Professor or Harmony, Analysis and Composition in School of Music of Federal University of Rio de Janeiro. Continuous activity and many musical works performed and recorded in Brazil and overseas. Resident composer of ABSTRAI Ensemble in the 2012 season with support of the Secretary of Culture of Rio de Janeiro State. Guest composer of the 2012 season of the group of composers Preludio 21. Prized twice with commissions for Contemporary Brazilian Music Biennials - 2013 
RAMOS, Bernardo; GENTIL-NUNES, Pauxy. Parsimonious relations between Guitar Textural Proposals. Revista Vórtex, Curitiba, v.8, n.3, p. $1-21,2020$.

and 2015 by National Foundation of Arts - FUNARTE. Participation, in 2015, as panelist and composer, in EXPO 2015 Milano, and in I Virtuosi XXI Century Festival, in Recife. Works on CDs National Symphony Orchestra plays Today Composers (2016) and Trio Paineiras plays Today Composers (2017). Participation in International Festival RC4 with his autoral concert, Liberjongo (2017). Member of ABSTRAI Ensemble since 2011. Member of the composers group Preludio 21 since 2019. ORCID: https://orcid.org/0000-0001-6810-9609. E-mail: pauxygnunes@musica.ufrj.br 